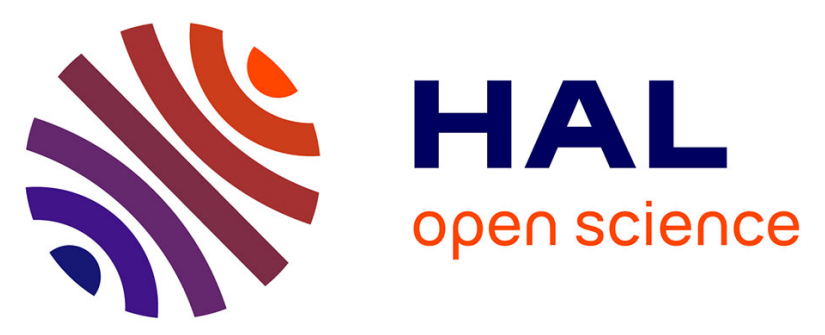

\title{
Effects of radiofrequency fields on RAS and ERK kinases activity in live cells using the Bioluminescence Resonance Energy Transfer technique
}

Emmanuelle Poque, Delia Arnaud-Cormos, Lorenza Patrignoni, Hermanus Johannes Ruigrok, F. Poulletier de Gannes, Annabelle Hurtier, Rémy Renom, André Garenne, Isabelle Lagroye, Philippe Lévêque, et al.

\section{To cite this version:}

Emmanuelle Poque, Delia Arnaud-Cormos, Lorenza Patrignoni, Hermanus Johannes Ruigrok, F. Poulletier de Gannes, et al.. Effects of radiofrequency fields on RAS and ERK kinases activity in live cells using the Bioluminescence Resonance Energy Transfer technique. International Journal of Radiation Biology, 2020, 10.1080/09553002.2020.1730016 . hal-03065159

\author{
HAL Id: hal-03065159 \\ https://hal.science/hal-03065159
}

Submitted on 14 Dec 2020

HAL is a multi-disciplinary open access archive for the deposit and dissemination of scientific research documents, whether they are published or not. The documents may come from teaching and research institutions in France or abroad, or from public or private research centers.
L'archive ouverte pluridisciplinaire HAL, est destinée au dépôt et à la diffusion de documents scientifiques de niveau recherche, publiés ou non, émanant des établissements d'enseignement et de recherche français ou étrangers, des laboratoires publics ou privés. 
International Journal of Radiation Biology

\section{Effects of radiofrequency fields on RAS and ERK kinases activity in live cells using the Bioluminescence Resonance Energy Transfer technique}

Emmanuelle Poque ${ }^{1}$, Delia Arnaud-Cormos ${ }^{2}$, Lorenza Patrignoni ${ }^{1}$, Hermanus J. Ruigrok ${ }^{1}$, Florence Poulletier De Gannes ${ }^{1}$, Annabelle Hurtier ${ }^{1}$, Rémy Renom ${ }^{1}$, André Garenne ${ }^{3}$, Isabelle Lagroye ${ }^{1,4}$, Philippe Leveque $^{2} \&$ Yann Percherancier ${ }^{1, *}$

${ }^{1}$ Bordeaux University, CNRS, IMS laboratory, UMR5218, F-33400 Talence, France

${ }^{2}$ Limoges University, CNRS, XLIM, UMR 7252, F-87000 Limoges, France

${ }^{3}$ Bordeaux University, CNRS, Institute of Neurodegenerative Diseases, UMR 5293, France

${ }^{4}$ Paris Sciences et Lettres Research University, F-75006 Paris, France

* correspondence to: yann.percherancier@ims-bordeaux.fr

Running Title: Radiofrequency effect on ERK and RAS kinases 


\section{Abstract-}

Purpose: The present study was conducted to re-evaluate the effect of low-level 1800 MHz RF signals (up to public exposure level for local exposure) on RAS/MAPK activation in live cells.

Material and methods: Using molecular probes based on the Bioluminescence Resonance Energy Transfer technique (BRET), we assessed the effect of Continuous wave (CW) and Global System for Mobile (GSM)-modulated $1800 \mathrm{MHz}$ signals (up to $2 \mathrm{~W} / \mathrm{kg}$ ) on ERK and RAS kinases' activity in live HuH7 cells.

Results: We found that radiofrequency field (RF) exposure for $24 \mathrm{~h}$ altered neither basal level of RAS and ERK activation nor the potency of phorbol-12-myristate-13-acetate (PMA) to activate RAS and ERK kinases, whatever the Specific Absorption Rate (SAR) or signal used. However, we found that exposure to GSM-modulated $1800 \mathrm{MHz}$ signals at $2 \mathrm{~W} / \mathrm{kg}$ decreased the PMA maximal efficacy to activate both RAS and ERK kinases' activity. Exposure with CW $1800 \mathrm{MHz}$ signal at $2 \mathrm{~W} / \mathrm{kg}$ only decreased maximal efficacy of PMA to activate ERK but not RAS. No effects of RF exposure at $0.5 \mathrm{~W} / \mathrm{kg}$ was observed on maximal efficacy of PMA to activate either RAS or ERK whatever the signal used.

Conclusion: Our results indicate that RF exposure decreases the efficiency of the cascade of events, which, from the binding of PMA to its receptor(s), leads to the activation of RAS and ERK kinases. This effect of RF exposure is reminiscent of RF-induced adaptive response.

Keywords - radiofrequency fields, BRET, kinases, phorbol ester, adaptive response 


\section{INTRODUCTION}

Over the last decades, the emergence of new technologies based on non-ionizing electromagnetic fields in the radiofrequency $(\mathrm{RF})$ range has occurred in many different areas of our daily life, and RF exposure has become ubiquitous. This has triggered societal concerns regarding potential health effects. While the energy per RF photon is not strong enough to induce direct chemical changes in the biological targets, the question remains as to whether RF fields could trigger cellular stress responses (IARC 2013).

One of the major mechanisms that trigger cellular responses to extracellular stimuli is the activation of Ser/Thr mitogen-activated protein-kinase (MAPK) cascades that relays extracellular signals to intracellular processes following activation of RAS (Kim \& Choi. 2015; Nussinov et al. 2018). The RAS/MAPK signalling pathway is playing a pivotal role in the regulation of various cellular processes such as gene expression, cellular growth, and survival. Within these signalling pathways, RAS activates the three MAPKs ERK, JNK, and p38. Abnormal MAPK signalling may lead to increased or uncontrolled cell proliferation and resistance to apoptosis, and has been shown to be implicated in numerous cancers (Kim \& Choi. 2015).

In the last twenty years, various research groups have investigated whether RF fields activated the RAS/MAPK cell stress response using standard biochemical and proteomics assays (Caraglia et al. 2005; Lee et al. 2006; Buttiglione et al. 2007; Friedman et al. 2007; Yu et al. 2008; Huang et al. 2008; Kim et al. 2012; Sheikh et al. 2013; Zhao et al. 2014; Liu et al. 2014; Valbonesi et al. 2014; Tang et al. 2015; Wang et al. 2015; Zuo et al. 2015; Shahin et al. 2018; Szymanski et al. 2018; Tsoy et al. 2019). All articles published until 2012 were reviewed by the International Agency for Research on Cancer (IARC) working group (IARC 2013) and discussed by Kim et al. (2012) (Kim et al. 2012). Since 2012, eleven studies from eight different research groups, reported experiments in which ERK activity was found (i) to 
be increased in murine microvascular endothelial cells, murine spermatocyte-derived cells (GC-2), differentiated PC-12 cells and ECV304 cell line (Sheikh et al. 2013; Liu et al. 2014; Zhao et al. 2014; Wang et al. 2015; Zuo et al. 2015), and (ii) to be decreased in rat and mice brain cells prepared from animals (Tang et al. 2015; Shahin et al. 2018; Tsoy et al. 2019) following RF exposure in the GHz range. Two studies performed in PC12-derived neuron-like cells and MCF10A human breast epithelial cells reported no effects of RF exposure on the RAS/MAPK pathway (Kim et al. 2012; Valbonesi et al. 2014) and one study reported that 900 $\mathrm{MHz}$ RF exposure for 4 to $24 \mathrm{~h}$ induced either an increase, a decrease, or no effect on the level of phosphorylated ERK depending on the cell type considered (HaCAT and PCS-200-010 human keratinocyte cell lines, and human primary keratinocytes derived from atopic dermatitis patients) (Szymanski et al. 2018). The overall conclusion is that whether RF exposure is able to induce a cell stress response via the RAS/MAPK is still controversial, requiring for more sensitive quantitative methods, ideally performed on live cells.

For the last fifteen years, resonance energy-transfer (RET)-based approaches have offered new opportunities for real-time probing for the activity of an ever-growing list of proteins in live cells (Miyawaki \& Niino. 2015). These techniques are based on the nonradiative transfer of energy between an energy donor and a compatible fluorescent energy acceptor. This approach allows for monitoring both constitutive and regulated inter- and intramolecular interactions, in view of the strict dependence on molecular proximity (around 100 $\AA$ ) and orientation between donor and acceptor molecules for energy transfer. Among the various RET techniques, Bioluminescence Resonance Energy Transfer (BRET) is a popular, broadly-applicable biophysical method that eliminates the need for an external light source for donor excitation. BRET thus circumvents problems inherent to Fluorescence Resonance Energy Transfer (FRET) imaging, or measurement, including (1) background fluorescence from cellular components and chemical compounds, (2) phototoxicity of excitation light, (3) 
photo-bleaching of the fluorophores, (4) incompatibility with optogenetic tools, and (5) invasive procedures for in-vivo microscopy (Pfleger \& Eidne. 2006). Thanks to these advantages, we recently have shown that BRET is useful for probing proteins interactions and conformational changes in live cells under chemical (Ruigrok et al. 2017) or RF exposure (Ruigrok et al. 2018).

The present study was therefore conducted to re-evaluate the effect of low-level 1800 MHz RF signals (up to public exposure level for local exposure) on RAS/MAPK activation in live cells using BRET-based molecular probes. We took advantage of already existing RAS and ERK FRET biosensors (Komatsu et al. 2011) that we modified into BRET probes. Using these new probes, we monitored both basal and phorbol-12-myristate-13-acetate (PMA)induced ERK and RAS activities in live human hepatocarcinoma $\mathrm{HuH7}$ cells exposed under isothermal conditions for $24 \mathrm{~h}$ to Continuous Wave (CW) and Global System for Mobile (GSM)-modulated $1800 \mathrm{MHz}$ RF fields at two different Specific Absorption Rate (SAR) levels: 0.5 and $2 \mathrm{~W} / \mathrm{kg}$.

\section{MATERIALS AND METHODS}

\section{Designing BRET probes-}

RAS and ERK BRET sensors were developed by replacing the fluorescent energy donor (ECFP or Turquoise-GL) of the EKAREV and RaichuEV-ras FRET probes described in Komatsu et al. (2011) (Komatsu et al. 2011) with Renilla Luciferase 8 (RLuc8, (Loening et al. 2006)). Mammalian expression vector coding ERK (pEKAREV) and RAS (pRaichuEV-Ras) FRET probes were kindly provided by Dr Matsuda M (Kyoto University, Japan). RLuc8 was first amplified by PCR from the pcDNA3-YFP-EPAC-Luc vector (a kind gift of M. Bouvier, Institute for Research in Immunology and Cancer, Montreal, Canada), using the Not1-ATGLuc-Sens primer (5'- 
AAGCTGGGCGGCCGCATGACCAGCAAGGTGTACGACCCCGAGC-3') and Luc-Xba1AS primer (5'- GCTGCAGTCTAGACTGCTCGTTCTTCAGCACTCTCTCC-3'). The Rluc8 amplicon was then cloned in place of the fluorescent energy donor, between $N$ ot $I$ and $X \mathrm{ba} I$, in pEKAREV and pRaichuEV-Ras expression vectors (Komatsu et al. 2011).

\section{Reagents-}

Phorbol-12-myristate-13-acetate (PMA) was acquired from Tocris (Bristol, UK), and Coelenterazine H from Nanolight Technology (Pinetop, AZ, USA).

\section{Cell culture and transfections-}

HuH7 human hepatocarcinoma cells were kindly provided by J. Rosenbaum (INSERM U889, Bordeaux University, Bordeaux, France) and were maintained in Dulbecco's modified Eagle's medium—-high glucose (Cat. No. D6429; Sigma-Aldrich, St. Louis, MO) supplemented with $10 \%$ fetal bovine serum, 100 units $\mathrm{mL}^{-1}$ penicillin and streptomycin. Twenty hours before transfection, cells were seeded at a density of 500,000 cells/well in 6well dishes. Transient transfections were performed using polyethylenimine (PEI, linear, Mr 25,000; Cat. No. 23966 Polysciences, Warrington, PA) with a PEI/DNA ratio of 4:1, as explained in Ruigrok et al. (2018) (Ruigrok et al. 2018). Typically, transient transfections were performed using $8 \mu \mathrm{g}$ PEI, $1 \mu \mathrm{g}$ of the BRET probe of interest and $1 \mu \mathrm{g}$ empty vector. After overnight incubation, cells were then detached, and plated at a density of $10^{5}$ cells into white-opaque 96-well plate (Greiner Bio One, les Ulis, France).

\section{BRET measurements-}

BRET measurements were done on attached cells as previously described (Ruigrok et al. 2018) except that, 6 hours before BRET measurement, the cell culture medium was 
replaced by red phenol-free DMEM containing $0.2 \%$ fetal bovine serum. Briefly, following $23 \mathrm{hrs}$ and $45 \mathrm{~min}$ of sham or RF exposures, cells were incubated for an additional $15 \mathrm{~min}$ with the indicated concentration of PMA under sham or RF exposure. Following PMA activation, Coelenterazine $\mathrm{H}$ was added to the cell culture medium at a final concentration of $5 \mu \mathrm{M}$ and the BRET signal was immediately acquired. BRET measurements were acquired using a Tristar-2 plate reader (Berthold, Bad Wildbad, Germany).

\section{RF field exposure system-}

The RF field exposure system consisted in a tri-plate open transverse electromagnetic (TEM) cell inside which the RF signals propagate (Ruigrok et al. 2017). The HuH7 cells were exposed to RF in a 96-well plate placed on the lower ground plate of the TEM cell. RF signals were delivered to the exposure system using a vector generator (SMBV100A, Rohde \& Schwarz, Munich, Germany) connected to a $10 \mathrm{~W}$ preamplifier and a $200 \mathrm{~W}$ amplifier (RF14002600-10, and RFS1800-200, RFPA, Artigues-Près-Bordeaux, France) with 39- and 9-dB gain, respectively. Investigations were carried out at two power levels and two $1800 \mathrm{MHz}$ RF signals (CW and GSM). For the CW signal, the power levels delivered by the vector generator were -14.2 and $-8.2 \mathrm{dBm}$ corresponding to incident powers at the TEM cell input of $32.2 \mathrm{dBm}(1.7 \mathrm{~W})$ and $38.2 \mathrm{dBm}(6.8 \mathrm{~W})$. CW and GSM signals had equal mean power value while the GSM peak value was eight-fold the mean value.

\section{Numerical and Experimental dosimetry-}

The SAR was assessed through numerical and experimental dosimetry. The RF field exposure system containing the 96-well plate with $\mathrm{HuH} 7$ cells was numerically modelled using an in-house Finite Difference Time Domain (FDTD) software (Fig. 1A). All metallic parts were considered as perfect conductors. The 96-well plate plastic dielectric permittivity 
was 2.5 . The cell culture medium of $100 \mu \mathrm{l}$ per well was modelled with a dielectric permittivity of 74.2 and an electrical conductivity of $2.64 \mathrm{~S} / \mathrm{m}$, values measured at $37^{\circ} \mathrm{C}$ at $1800 \mathrm{MHz}$ using a dielectric probe (85070E, Agilent, USA). Simulations were performed with a spatial meshing of $200 \mu \mathrm{m}$ for the culture medium in the 96 wells. SAR values were extracted from simulation for (i) the culture medium whole volume, ii) the bottom layer at the cells level and (iii) SAR Probe corresponding to the temperature probe measurement volume (1-mm diameter and height cylinder).

Experimental SAR values were assessed from temperature variations using the following equation (1):

(1) $S A R=\left.4186 c \frac{\Delta T}{\Delta t}\right|_{t_{0}}$

where $c$, the specific heat scale factor, equals $0.95,4186$ is the sample specific heat expressed in $\mathrm{J} /(\mathrm{kg} \mathrm{K})$, and $\square T / \square t$ is the initial slope of the temperature curve.

Temperature measurements were acquired using a non-perturbing optical fibre probe (Luxtron-812, Lumasense Technologies, Santa Clara, USA) placed at the centre at the bottom of the $100-\mu l$ filled well. The temperature variation was assessed for different wells within the 96-well plate for a $39.1 \mathrm{dBm}(8.15 \mathrm{~W})$ incident power. Fig. 1B illustrates this SAR spatial distribution. The SAR distribution among the 96 wells is rather homogeneous. SAR values normalized for $1 \mathrm{~W}$ incident power were extracted from simulations: whole volume $(0.27 \pm$ $0.12 \mathrm{~W} / \mathrm{kg})$, and bottom layer $(0.32 \pm 0.05 \mathrm{~W} / \mathrm{kg})$, corresponding to the localized temperature probe $(0.25 \pm 0.04 \mathrm{~W} / \mathrm{kg})$. The comparison of averaged simulated and measured $(0.30 \pm 0.05$ $\mathrm{W} / \mathrm{kg}$ ) localized SAR shows a good agreement. The SAR bottom layer values corresponding to the incident powers of $1.7 \mathrm{~W}$ and $6.8 \mathrm{~W}$ are $0.54 \pm 0.06 \mathrm{~W} / \mathrm{kg}$ and $2.16 \pm 0.41 \mathrm{~W} / \mathrm{kg}$, respectively. No temperature difference was observed in the culture medium of cells exposed 
at $0.5 \mathrm{~W} / \mathrm{kg}$ while temperature increased by $0.5{ }^{\circ} \mathrm{C}$ under exposure to $2 \mathrm{~W} / \mathrm{Kg}$. This slight temperature increase was counterbalanced by decreasing the temperature of the incubator containing the RF field exposure system by $0.5{ }^{\circ} \mathrm{C}$ relative to the sham incubator that was mainained at $37^{\circ} \mathrm{C}$.

\section{Data and Statistical analysis-}

GraphPad Prism v6.00 for Windows (GraphPad Software, La Jolla, CA, USA) was used for plotting dose-response curves. Statistical analyses were performed using Anastats (Rilly sur Vienne, France). The one sample Wilcoxon signed-rank test was used to assess the statistical significance against the null hypothesis of the difference calculated between Sham and RF field condition for basal BRET, PMA potency and efficacy. P-values less than 0.05 were considered as statistically significant. 


\section{RESULTS}

The hypothesis that RF fields specifically induce RAS or ERK activity or impact chemically-induced RAS or ERK activity in live cells was tested using a BRET based assay. In that protocol, we took advantage of previously described RAS and ERK FRET probes (Komatsu et al. 2011) that we modified into BRET probes by replacing the cyan fluorescent protein energy donor with Renilla Luciferase (see material and methods). These new RAS and ERK BRET probes comprise therefore a sensor domain and a ligand domain connected by a flexible linker, a yellow Fluorescent protein (YFP) serving as energy acceptor and Renilla Luciferase serving as energy donor in place of the Cyan Fluorescent protein in the original FRET probes (see material and methods). The sensor domain changes its conformation upon action of either RAS or ERK endogenous protein. This sensitized sensor domain interacts with the ligand domain, thereby inducing a global change of the biosensor conformation and a concomitant increase of the BRET efficiency from the donor to the acceptor (Fig. 2A).

To assess the effect of RAS/MAPK activation on the BRET signal measured using both RAS and ERK BRET probes, we first transfected $\mathrm{HuH7}$ cells with the cDNA coding either the EKAREV BRET probe or the Raichu-Ras BRET probe and we challenged transfected cells with different amounts of PMA for 15 min before BRET measurement. As expected, basal BRET ratio measured for RAS and ERK probes $(0.623 \pm 0.012$ and $0.596 \pm 0.012$, respectively) dose-dependently increased following activation with PMA with potencies in the nanomolar range, demonstrating the high sensitivity of our BRET-based assay to monitor RAS and ERK activation (Fig. 2 B\&C).

We then assessed the effect of increasing concentration of PMA on RAS (Fig. 3 A-D) and ERK (fig. 4 A-D) activities in $\mathrm{HuH} 7$ cells that were exposed for $24 \mathrm{~h}$ to $1800 \mathrm{MHz} \mathrm{CW}$ or GSM signals at two different SARs: $0.5 \mathrm{~W} / \mathrm{kg}$ and $2 \mathrm{~W} / \mathrm{kg}$, while keeping the cell culture medium at $37^{\circ} \mathrm{C}$. Analysis of the resulting dose-response curve indicates that the basal BRET 
ratio of RAS (Fig. 3E) and ERK (Fig. 4E) as well as the PMA potency to activate these kinases (Fig. 3F for RAS and Fig. 4F for ERK) were not modified when $\mathrm{HuH7}$ cells were exposed to the RF field, whatever the SAR $(0.5$ and $2 \mathrm{~W} / \mathrm{Kg})$ or RF signal (CW or GSM) used. No effect of RF field exposure could also be measured on PMA maximal efficacy to activate RAS and ERK kinases, at $0.5 \mathrm{~W} / \mathrm{kg}$, whatever the signal used (CW or GSM). However, we measured a modest but statistically significant decrease $(\sim 20 \%)$ in PMA maximal efficacy to activate RAS and ERK in $\mathrm{HuH7}$ cells exposed to the $1800 \mathrm{MHz}$ GSM signal at $2 \mathrm{~W} / \mathrm{kg}$ in comparison to the non-exposed condition (sham) (fig. 3D and G for RAS and fig.4D and G for ERK). The $1800 \mathrm{MHz} \mathrm{CW}$ signal at $2 \mathrm{~W} / \mathrm{kg}$ also induced a decrease in PMA maximal efficacy to activate ERK (Fig. 4C and G), but failed to modify PMA maximal efficacy to activate RAS (fig. 3C and G).

\section{Discussion}

In this study, we first adapted previously-described sensitive FRET probes for the detection of RAS and ERK activities in live cells using the BRET technique. Taking advantage of these new BRET probes, we then evaluated the effect of CW and GSM modulated $1800 \mathrm{MHz}$ RF fields at two different SAR (0.5 and $2 \mathrm{~W} / \mathrm{kg})$ for $24 \mathrm{~h}$ under isothermal conditions at $37^{\circ} \mathrm{C}$ on live $\mathrm{HuH7}$ cells. The upper SAR value corresponds to the upper limit of the standards for local exposure of the human head according to the International Commission on Non-Ionizing Radiation Protection (ICNIRP) guidelines for public exposure (ICNIRP. 1998). While we couldn't evidence a direct effect from RF radiation alone on RAS and ERK activities, we also investigated the possibility that RF fields could interact with a known inducer of RAS/ERK . In this study, we used the well-known phorbol-ester PMA as an activating chemical agent for RAS and ERK kinases. PMA is a small molecule drug that substitutes for diacylglycerol and activates the signal transduction 
enzyme protein kinase $\mathrm{C}$ (PKC) by directly binding to its $\mathrm{C} 1$ domains (Castagna et al. 1982), which can lead to PKC-dependent RAS and ERK activation in several cell lines including HuH7 (Hatzis et al. 2006). Alternatively, PMA can also stimulate the Ras/Raf/MEK/ERK pathway through direct binding and activation of RasGRPs proteins (Brose \& Rosenmund. 2002). Commonly, PMA is employed as a tumour-promoting agent for skin carcinogenesis in rodents and is associated with increased cell proliferation in malignant cells from several types of tumours, such as melanoma and breast and oral cancer (Fukushima et al. 2016; Lii et al. 2016). Our results show that, under our experimental conditions, RF field exposure alone does not affect the basal activity of ERK and RAS kinases nor modifies the PMA potency to activate these kinases, whatever the signal or SAR used. However, our results indicate that GSM-modulated $1800 \mathrm{MHz}$ signal at $2 \mathrm{~W} / \mathrm{kg}$ can decrease the PMA maximal efficacy to activate both RAS and ERK. The maximal efficacy of PMA to activate ERK kinase, but not RAS, was also decreased following cells' exposure to unmodulated $1800 \mathrm{MHz}$ RF (CW signal) emitted at $2 \mathrm{~W} / \mathrm{kg}$.

The absence of variation in the basal BRET ratio following RF field exposure (Fig. 3E and 4E) indicates that such exposure does not modify RAS and ERK expression levels nor their basal activities in absence of chemical activation. Lack of shift in the potency by which PMA, acting via various defined or undefined mechanisms of action, can lead to RAS and ERK activation (Fig. 3F and 4F) indicates that both PMA affinity for its receptors (whatever they are) and its ability to alter the functional intrinsic activity of RAS and ERK kinases are not modified by RF field exposure. Strikingly, the decrease in PMA maximal efficacy to activate RAS (Fig. 3G) and ERK (Fig. 4G) following RF field exposure of the cells at $2 \mathrm{~W} / \mathrm{kg}$ is a measure of a lower capability to achieve maximal ERK and RAS activation. Our results therefore preclude any change of the PMA ligand binding probability due to low intensity RF field exposure as discussed by Chiabrera et al (2000) (Chiabrera et al, 2000). Our data instead 
point to a decrease of the receptor coupling efficiency, i.e., from the cascade of events which, from the binding of PMA to its receptor(s), leads to the activation of RAS and ERK kinases.

Several studies in the last decade have shown that pre-exposure to RF fields emitted at level below the current guidelines can prime an adaptive response in the cell population, i.e. can exhibit a decrease in the genotoxic response to a subsequent high dose of ionizing radiation or chemical agent (Cao et al. 2010; Cao et al. 2011; Vijayalaxmi \& Scarfi. 2014; Cao \& Tong. 2014; Falone et al. 2018). Our results showing that RF fields can decrease the ERK and/or RAS kinase activity in response to PMA are in agreement with the concept of an adaptive response triggered by RF field exposure. This phenomenon is here only observed at $2 \mathrm{~W} / \mathrm{kg}$, indicating the existence of a threshold. Moreover, the differential decrease in PMA efficacy to activate ERK and/or RAS after unmodulated and GSM-modulated $1800 \mathrm{MHz}$ signal exposure $(2 \mathrm{~W} / \mathrm{kg})$ suggests that modulation and/or bandwidth might be an important factor in the context of RF-induced adaptive response, as indicated by a recent study (Romeo et al. 2019). To better characterize whether our results are indicative of an adaptive response, further experiments should be carried out on various parameters of RF exposure such as duration of the RF exposure, resting time between RF and chemical exposure, and characteristics of the RF signal (modulation, bandwidth, carrier frequency, SAR...).

Our observations also indicate that RF field exposure can decrease PMA-induced ERK activation independently of RAS activation. Interestingly, it was previously reported that PMA can lead to ERK activation independently of RAS activation (Ueda et al. 1996).

In summary, our results suggest that RF field exposure may affect the chemicallyinduced RAS/MAPK pathway at various steps and this effect seems compatible with an adaptive response. An adaptive response to low doses of radiation or chemicals is probably the result of a multifaceted cellular programme involving the concerted action of diverse stress response pathways, among which is the RAS/MAPK signalling pathway (Guéguen et 
al. 2019). The description of the interplay between all these molecular mechanisms to achieve the adaptive response is still to be explored. In this context, BRET probes are powerful tools for understanding how RF fields activate an adaptive response and more generally to dissect the molecular mechanisms of an adaptive response.

\section{AbBreviation}

BRET: Bioluminescence Resonance energy Transfer

CW: Continuous wave

FDTD: Finite Difference-Time Domain method

GSM: Global System for Mobile

Luc: Luciferase

PMA: phorbol-12-myristate-13-acetate

MAPK: Ser/Thr mitogen-activated protein kinase

RF: radiofrequency.

SAR: Specific Absorption Rate

YFP: Yellow Fluorescent protein

\section{ACKNOWLEDGMENTS}

We thank Bernard Veyret for his wise advice and proofreading of the manuscript.

\section{FUNDING SOURCE}

The research leading to these results received funding from the European Community's Seventh Framework Programme (FP7/2007-2013) under grant agreement no. 603794 (the GERONIMO project). This study was performed within the framework of COST action EMFMED (BM1309) supported by COST (European Cooperation in Science and Technology). 


\section{DECLARATION OF INTEREST}

The authors declare no competing interests.

\section{AUTHORS' CONTRIBUTIONS}

YP conceived and designed the study. PL and DAC designed the device and performed the electromagnetic dosimetry. EP, LP, HJR, FPDG, AH, RR and YP collected and assembled the data. AG performed the statistical analysis of the results. YP, IL, DAC and PL wrote the manuscript. All co-authors read and approved the final manuscript.

\section{REFERENCES}

Brose N, Rosenmund C. 2002. Move over protein kinase C, you've got company: alternative cellular effectors of diacylglycerol and phorbol esters. J Cell Sci. 115: 4399-4411.

Buttiglione M, Roca L, Montemurno E, Vitiello F, Capozzi V, Cibelli G. 2007. Radiofrequency radiation (900 MHz) induces Egr-1 gene expression and affects cell-cycle control in human neuroblastoma cells. J Cell Physiol. 213: 759-767.

Cao Y, Tong J. 2014. Adaptive response in animals exposed to non-ionizing radiofrequency fields: some underlying mechanisms. Int J Environ Res Public Health. 11: $4441-4448$.

Cao Y, Xu Q, Jin ZD, Zhang J, Lu MX, Nie JH, Tong J. 2010. Effects of 900-MHz microwave radiation on gamma-ray-induced damage to mouse hematopoietic system. J Toxicol Environ Health A. 73: 507-513.

Cao Y, Xu Q, Jin ZD, Zhou Z, Nie JH, Tong J. 2011. Induction of adaptive response: pre-exposure of mice to $900 \mathrm{MHz}$ radiofrequency fields reduces hematopoietic damage caused by subsequent exposure to ionising radiation. Int J Radiat Biol. 87: 720-728. 
Caraglia M, Marra M, Mancinelli F, D'Ambrosio G, Massa R, Giordano A, Budillon A, Abbruzzese A, Bismuto E. 2005. Electromagnetic fields at mobile phone frequency induce apoptosis and inactivation of the multi-chaperone complex in human epidermoid cancer cells. J Cell Physiol. 204: 539-548.

Castagna M, Takai Y, Kaibuchi K, Sano K, Kikkawa U, Nishizuka Y. 1982. Direct activation of calcium-activated, phospholipid-dependent protein kinase by tumor-promoting phorbol esters. J Biol Chem. 257: 7847-7851.

Chiabrera AAB, Giordano BA, Bruna SA, Moggia SA, Kaufman EA, J. J (2000) Ligand Binding under RF EM Exposure. In Radio Frequency Radiation Dosimetry and Its Relationship to the Biological Effects of Electromagnetic Fields, Klauenberg BJMD (eds) pp 429-447. Dordrecht: Springer Netherlands

Falone S, Sannino A, Romeo S, Zeni O, Santini SJ, Rispoli R, Amicarelli F, Scarfî MR. 2018. Protective effect of $1950 \mathrm{MHz}$ electromagnetic field in human neuroblastoma cells challenged with menadione. Sci Rep. 8: 13234.

Friedman J, Kraus S, Hauptman Y, Schiff Y, Seger R. 2007. Mechanism of short-term ERK activation by electromagnetic fields at mobile phone frequencies. Biochem J. 405: 559568.

Fukushima K, Takahashi K, Fukushima N, Honoki K, Tsujiuchi T. 2016. Different effects of GPR120 and GPR40 on cellular functions stimulated by 12-Otetradecanoylphorbol-13-acetate in melanoma cells. Biochem Biophys Res Commun. 475: 2530.

González-Vera JA, Morris MC. 2015. Fluorescent Reporters and Biosensors for Probing the Dynamic Behavior of Protein Kinases. Proteomes. 3: 369-410. 
Guéguen Y, Bontemps A, Ebrahimian TG. 2019. Adaptive responses to low doses of radiation or chemicals: their cellular and molecular mechanisms. Cell Mol Life Sci. 76: 12551273.

Hatzis P, Kyrmizi I, Talianidis I. 2006. Mitogen-activated protein kinase-mediated disruption of enhancer-promoter communication inhibits hepatocyte nuclear factor 4alpha expression. Mol Cell Biol. 26: 7017-7029.

Huang TQ, Lee MS, Oh EH, Kalinec F, Zhang BT, Seo JS, Park WY. 2008. Characterization of biological effect of $1763 \mathrm{MHz}$ radiofrequency exposure on auditory hair cells. Int J Radiat Biol. 84: 909-915.

IARC Working Group on the Evaluation of Carcinogenic Risks to Humans.2013. Nonionizing radiation, Part 2: Radiofrequency electromagnetic fields. IARC Monogr Eval Carcinog Risks Hum. 102: 1-460.

ICNIRP.1998. Guidelines for limiting exposure to time-varying electric, magnetic, and electromagnetic fields (up to $300 \mathrm{GHz}$ ). International Commission on Non-Ionizing Radiation Protection. Health Phys. 74: 494-522.

Kim EK, Choi EJ. 2015. Compromised MAPK signaling in human diseases: an update. Arch Toxicol. 89: 867-882.

Kim HN, Han NK, Hong MN, Chi SG, Lee YS, Kim T, Pack JK, Choi HD, Kim N, Lee JS. 2012. Analysis of the cellular stress response in MCF10A cells exposed to combined radio frequency radiation. J Radiat Res. 53: 176-183.

Komatsu N, Aoki K, Yamada M, Yukinaga H, Fujita Y, Kamioka Y, Matsuda M. 2011. Development of an optimized backbone of FRET biosensors for kinases and GTPases. Mol Biol Cell. 22: 4647-4656. 
Lee JS, Huang TQ, Kim TH, Kim JY, Kim HJ, Pack JK, Seo JS. 2006. Radiofrequency radiation does not induce stress response in human T-lymphocytes and rat primary astrocytes. Bioelectromagnetics. 27: 578-588.

Lii CK, Chang JW, Chen JJ, Chen HW, Liu KL, Yeh SL, Wang TS, Liu SH, Tsai CH, Li CC. 2016. Docosahexaenoic acid inhibits 12-O-tetradecanoylphorbol-13-acetate-induced fascin-1-dependent breast cancer cell migration by suppressing the $\mathrm{PKC} \delta$ - and $\mathrm{Wnt}-1 / \beta$ catenin-mediated pathways. Oncotarget. 7: 25162-25179.

Liu K, Zhang G, Wang Z, Liu Y, Dong J, Dong X, Liu J, Cao J, Ao L, Zhang S. 2014. The protective effect of autophagy on mouse spermatocyte derived cells exposure to 1800MHz radiofrequency electromagnetic radiation. Toxicol Lett. 228: 216-224.

Loening AM, Fenn TD, Wu AM, Gambhir SS. 2006. Consensus guided mutagenesis of Renilla luciferase yields enhanced stability and light output. Protein Eng Des Sel. 19: 391400.

Miyawaki A, Niino Y. 2015. Molecular spies for bioimaging--fluorescent protein-based probes. Mol Cell. 58: 632-643.

Nussinov R, Tsai CJ, Jang H. 2018. Oncogenic Ras Isoforms Signaling Specificity at the Membrane. Cancer Res. 78: 593-602.

Pfleger KD, Eidne KA. 2006. Illuminating insights into protein-protein interactions using bioluminescence resonance energy transfer (BRET). Nat Methods. 3: 165-174.

Romeo S, Sannino A, Zeni O, Angrisani L, Massa R, Scarfi MR. 2019. Effects of Radiofrequency Exposure and Co-Expo-sure on Human Lymphocytes: the Influence of Signal Modulation and Bandwidth IEEE Journal of Electromagnetics, RF and Microwaves in Medicine and Biology. : 1-1.

Ruigrok HJ, Arnaud-Cormos D, Hurtier A, Poque E, de Gannes FP, Ruffié G, Bonnaudin F, Lagroye I, Sojic N, Arbault S, Lévêque P, Veyret B, Percherancier Y. 2018. 
Activation of the TRPV1 Thermoreceptor Induced by Modulated or Unmodulated $1800 \mathrm{MHz}$ Radiofrequency Field Exposure. Radiat Res. 189: 95-103.

Ruigrok HJ, Shahid G, Goudeau B, Poulletier de Gannes F, Poque-Haro E, Hurtier A, Lagroye I, Vacher P, Arbault S, Sojic N, Veyret B, Percherancier Y. 2017. Full-Spectral Multiplexing of Bioluminescence Resonance Energy Transfer in Three TRPV Channels. Biophys J. 112: 87-98.

Shahin S, Banerjee S, Swarup V, Singh SP, Chaturvedi CM. 2018. From the Cover: 2.45-GHz Microwave Radiation Impairs Hippocampal Learning and Spatial Memory: Involvement of Local Stress Mechanism-Induced Suppression of iGluR/ERK/CREB Signaling. Toxicol Sci. 161: 349-374.

Sheikh AQ, Taghian T, Hemingway B, Cho H, Kogan AB, Narmoneva DA. 2013. Regulation of endothelial MAPK/ERK signalling and capillary morphogenesis by lowamplitude electric field. J R Soc Interface. 10: 20120548.

Szymanski L, Cios A, Lewicki S, Szymanski P, Stankiewicz W. 2018. Fas/FasL pathway and cytokines in keratinocytes in atopic dermatitis - Manipulation by the electromagnetic field. PLoS One. 13: e0205103.

Tang J, Zhang Y, Yang L, Chen Q, Tan L, Zuo S, Feng H, Chen Z, Zhu G. 2015. Exposure to $900 \mathrm{MHz}$ electromagnetic fields activates the mkp-1/ERK pathway and causes blood-brain barrier damage and cognitive impairment in rats. Brain Res. 1601: 92-101.

Tsoy A, Saliev T, Abzhanova E, Turgambayeva A, Kaiyrlykyzy A, Akishev M, Saparbayev S, Umbayev B, Askarova S. 2019. The Effects of Mobile Phone Radiofrequency Electromagnetic Fields on $\beta$-Amyloid-Induced Oxidative Stress in Human and Rat Primary Astrocytes. Neuroscience. 408: 46-57. 
Ueda Y, Hirai Si, Osada Si, Suzuki A, Mizuno K, Ohno S. 1996. Protein kinase C activates the MEK-ERK pathway in a manner independent of Ras and dependent on Raf. $\mathrm{J}$ Biol Chem. 271: 23512-23519.

Valbonesi P, Franzellitti S, Bersani F, Contin A, Fabbri E. 2014. Effects of the exposure to intermittent $1.8 \mathrm{GHz}$ radio frequency electromagnetic fields on HSP70 expression and MAPK signaling pathways in PC12 cells. Int J Radiat Biol. 90: 382-391.

Vijayalaxmi C, Scarfi MR. 2014. Adaptive response in mammalian cells exposed to non-ionizing radiofrequency fields: A review and gaps in knowledge. Mutat Res Rev Mutat Res. 760: pp. 36-pp. 45.

Wang LF, Li X, Gao YB, Wang SM, Zhao L, Dong J, Yao BW, Xu XP, Chang GM, Zhou HM, Hu XJ, Peng RY. 2015. Activation of VEGF/Flk-1-ERK Pathway Induced BloodBrain Barrier Injury After Microwave Exposure. Mol Neurobiol. 52: 478-491.

Yu Y, Yao K, Wu W, Wang K, Chen G, Lu D. 2008. Effects of exposure to $1.8 \mathrm{GHz}$ radiofrequency field on the expression of Hsps and phosphorylation of MAPKs in human lens epithelial cells. Cell Res. 18: 1233-1235.

Zhao L, Yang YF, Gao YB, Wang SM, Wang LF, Zuo HY, Dong J, Xu XP, Su ZT, Zhou HM, Zhu LL, Peng RY. 2014. Upregulation of HIF-1 $\alpha$ via activation of ERK and PI3K pathway mediated protective response to microwave-induced mitochondrial injury in neuronlike cells. Mol Neurobiol. 50: 1024-1034.

Zuo H, Lin T, Wang D, Peng R, Wang S, Gao Y, Xu X, Zhao L, Wang S, Su Z. 2015. RKIP Regulates Neural Cell Apoptosis Induced by Exposure to Microwave Radiation Partly Through the MEK/ERK/CREB Pathway. Mol Neurobiol. 51: 1520-1529. 


\section{FIGURES LEGENDS}

FIG. 1. RF field exposure system. A) Numerical modeling of the TEM cell containing the 96-well plate with HuH7 cells in culture medium. B) SAR spatial distribution within the bottom layer of the 96-well plate exposed to $1800 \mathrm{MHz}, 1 \mathrm{~W}$ incident power.

FIG. 2. Mode of action and characterization of the intramolecular RAS and ERK BRET biosensors. A) In the presence of active endogenous kinase, which phosphorylates the substrate sequence of the biosensor, the phosphoamino acid-binding domain is prompted to bind the phosphorylated substrate peptide, thereby bringing Luc and YFP in close proximity. This intramolecular conformational change favors bioluminescent resonance energy transfer between the bioluminescent donor and the fluorescent acceptor, which results in an increase in fluorescence intensity of the acceptor, and a concomitant decrease in the bioluminescent intensity of the donor. Adapted from (González-Vera \& Morris. 2015). B and C) Doseresponse curves of PMA-induced change in RAS activity using the pRaichuEV-Ras BRET probe (B) and in ERK activity using the pEKAREV BRET probe (C) 36 to $48 \mathrm{~h}$ after transfection in $\mathrm{HuH} 7$ cells, cells were activated for 15 min at $37^{\circ} \mathrm{C}$ with increasing concentration of PMA before BRET measurement. The results represent the average \pm S.E.M. of 24 (RAS) and 28 (ERK) independent experiments done in duplicate. The pEC50 of PMA was $8.54 \pm 0.29$ for pRaichuEV-Ras BRET probe and $8.69 \pm 0.22$ for pEKAREV BRET probes. PMA activated the pRaichuEV-Ras and pEKAREV BRET probes with a maximal efficacy of $0.103 \pm 0.021$ and $0.121 \pm 0.020$ respectively.

FIG. 3. Effect of RF field exposure on basal and PMA-induced RAS activity. A-D) HuH7 cells transfected with the pRaichuEV-Ras BRET probe were sham-exposed or exposed 
to unmodulated CW $1800 \mathrm{MHz}$ (A and C) or GSM-modulated $1800 \mathrm{MHz}$ (B and D) signals at either $0.5 \mathrm{~W} / \mathrm{kg}(\mathrm{A}$ and $\mathrm{B})$ or $2 \mathrm{~W} / \mathrm{kg}(\mathrm{C}$ and $\mathrm{D})$ for $23 \mathrm{~h}$ and $45 \mathrm{~min}$. Cells were then activated with increasing concentration of PMA under sham or RF field exposure for 15 min before BRET measurement. The results represent the average \pm S.E.M. for the effect of CW RF field at $0.5 \mathrm{~W} / \mathrm{kg}(\mathrm{n}=5), \mathrm{GSM}-$ modulated field at $0.5 \mathrm{~W} / \mathrm{kg}(\mathrm{n}=6), \mathrm{CW} \mathrm{RF}$ field at $2 \mathrm{~W} / \mathrm{kg}(\mathrm{n}=4)$ and GSM-modulated field at $2 \mathrm{~W} / \mathrm{kg}(\mathrm{n}=8)$. The indicated independent experiments were done in duplicate. E-G) Box and whisker plots representing the distribution of the variations of basal BRET (E), PMA potency (F) and PMA maximal efficacy (G) between the RF field exposed- (Expo) and sham- conditions derived for each experimental conditions plotted in AD. Statistical significance of the derivation from the null hypothesis (no difference between sham and RF field exposure) was assessed using the one-Sample Wilcoxon Signed Rank Test. n.s.: not significant; $*$ : $p<0.5 ; * *$ : $p<0.1$.

FIG. 4. Effect of RF field exposure on basal and PMA-induced ERK activity. A-D) HuH7 cells transfected with the pEKAREV BRET probe were sham-exposed or exposed to unmodulated, CW $1800 \mathrm{MHz}$ (A and C) or GSM-modulated $1800 \mathrm{MHz}$ (B and D) signals at either $0.5 \mathrm{~W} / \mathrm{kg}(\mathrm{A}$ and $\mathrm{B})$ or $2 \mathrm{~W} / \mathrm{kg}(\mathrm{C}$ and $\mathrm{D})$ for $23 \mathrm{~h}$ and $45 \mathrm{~min}$. Cells were then activated with increasing concentration of PMA under sham or RF field exposure for 15 min before BRET measurement. The results represent the average \pm S.E.M. for the effect of $\mathrm{CW}$ and GSM-modulated fields at $0.5 \mathrm{~W} / \mathrm{kg}(\mathrm{n}=6), \mathrm{CW}$ RF field at $2 \mathrm{~W} / \mathrm{kg}(\mathrm{n}=6)$ and GSM-modulated field at $2 \mathrm{~W} / \mathrm{kg}(\mathrm{n}=8)$. Independent experiments were done in duplicate. $\mathrm{E}-\mathrm{G})$ Box and whisker plots representing the distribution of the variations of basal BRET (E), PMA potency (F) and PMA maximal efficacy $(\mathrm{G})$ between the RF field exposed (Expo) and sham conditions derived for each experimental conditions plotted in A-D. Statistical significance of the derivation from the null hypothesis (no difference between sham and RF exposure) was 
assessed using the one-Sample Wilcoxon Signed Rank Test. n.s.: not significant; *: $\mathrm{p}<0.5 ; * *$ : $\mathrm{p}<0.1$. 
A

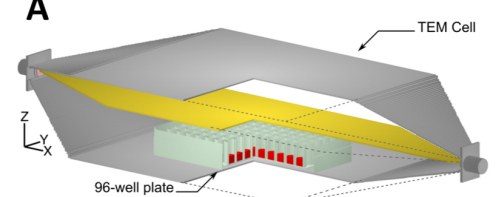

B

А B 000000000000 SAR (W/Ka c 000000000000

0000000000000 EOO0000000000

FO 00000000000

6000000000000

н

Figure 1: 
A

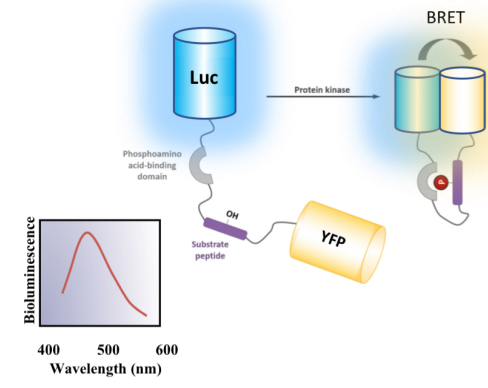

B

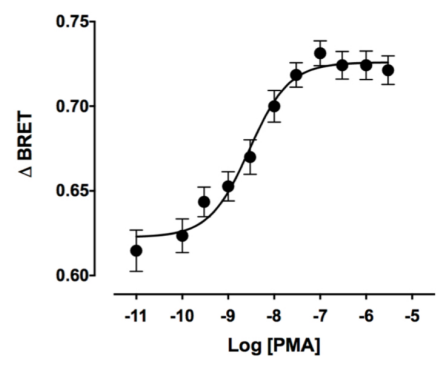

C

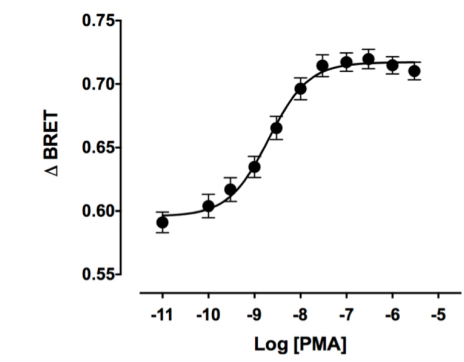

Figure 2:

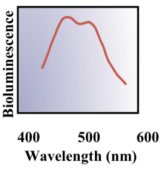


A

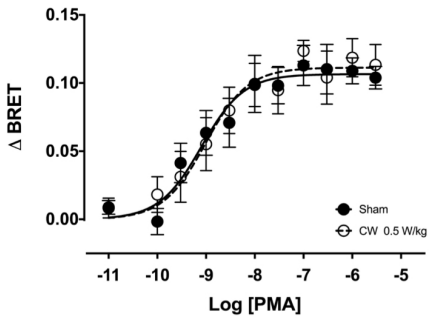

C

D

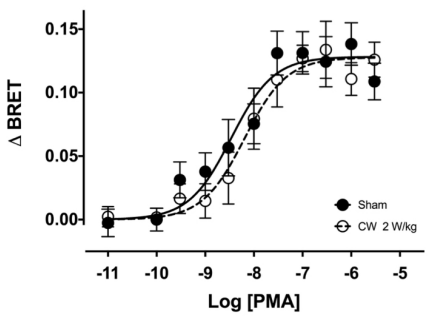

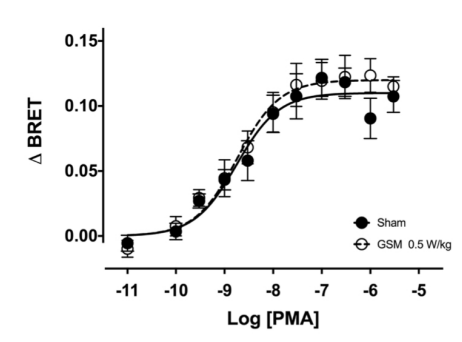

B

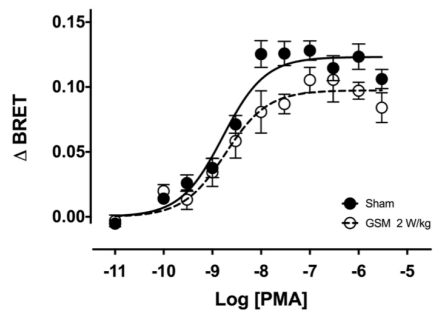

E

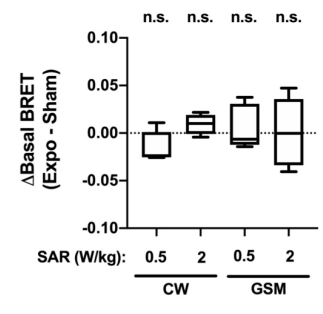

F

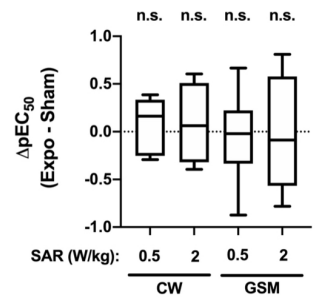

G

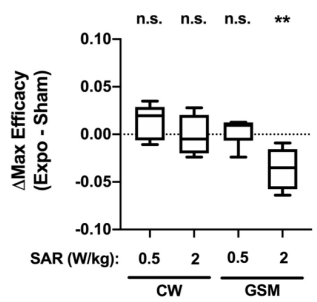

Figure 3: 
A

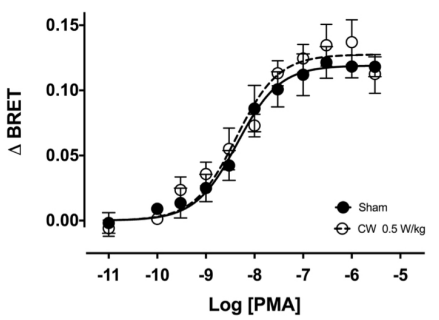

C

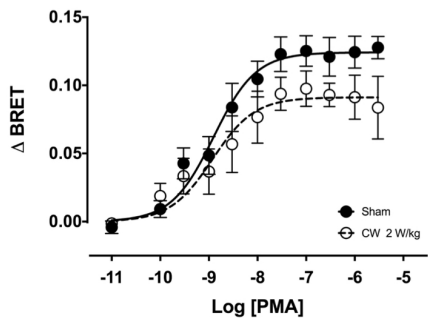

B

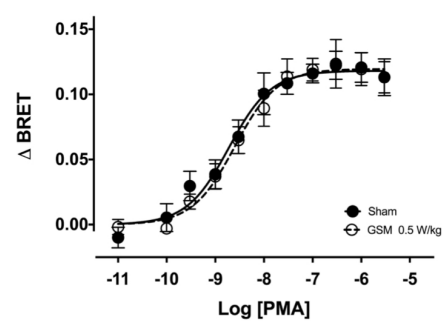

D

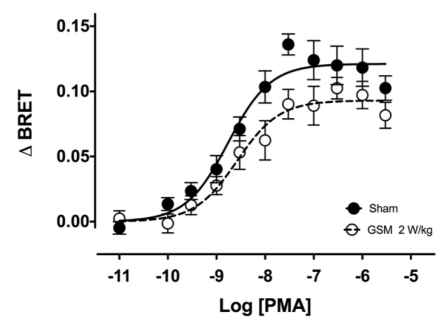

E

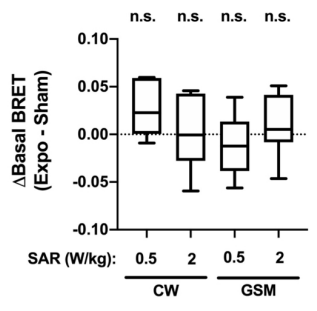

F

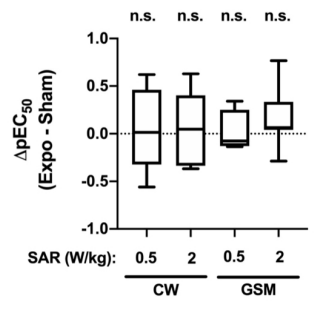

G

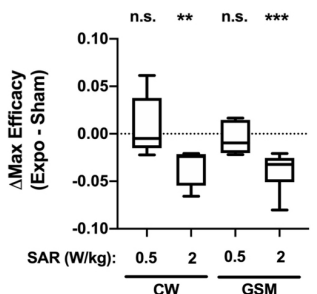

Figure 4: 